\title{
Articular cartilage changes in Caucasian and Asian hip joints
}

\author{
P. D. BYERS*, F. T. HOAGLUND $\dagger$, G. S. PUREWAL $\ddagger$, ANd A. C. M. C. YAU§ \\ From the * Institute of Orthopaedics, Royal National Orthopaedic Hospital, London, the \\ $\dagger$ Department of Orthopaedic Surgery, University of Vermont College of Medicine, Burlington, U.S.A., the \\ $\ddagger$ Department of Orthopaedics, Medical College, V.J. Hospital, Amritsar, Punjab, India, and the \\ $\S$ Department of Orthopaedic Surgery, University of Hong Kong, Queen Mary Hospital, Hong Kong
}

Byers, Contepomi, and Farkas (1970) proposed for the hip joint two classes of articular cartilage change, those of limited progression which do not lead to joint deformity, and a progressive group which represents the changes of osteoarthrosis. In the Caucasian population that they studied, the latter lesions affected about 4 per cent. while the former affected a very large number which increased with age, reaching a maximum of 80 per cent. in the 7 th decade for the most prevalent feature. One test of their hypothesis would be an examination of Asian hip joints in which primary osteoarthrosis occurs only rarely. Hoaglund, Yau, and Wong (1973) estimate the incidence of Grade 3 and 4 osteoarthritis of the hip in Hong Kong Chinese at $\mathbf{0 . 6}$ per cent. for males and 0 per cent. for females. Mukhopadhaya and Barooah (1967) gave a figure of 0.1 per cent. for an Indian population, without specifying their criteria. Notwithstanding that the relatively small number of progressive lesions demands the inspection of a very large number of hip joints before statistically valid statements can be made, the presence in Asian hip joints of changes similar to those of limited progression in Caucasians would be strong substantiation of their hypothesis. So far it has proved possible to examine and classify only eleven femoral heads from an Indian population and 32 Chinese hip joints from Hong Kong. Because of the complexities and slowness of conducting a large-scale study, it seemed worth while to report the findings from this small number of cases.

\section{Material}

The Indian specimens were obtained post mortem at V.J. Hospital, Amritsar, India. The age distribution is shown in Table $I$.

The Chinese hip joints were obtained post mortem at Queen Mary Hospital, Hong Kong. The age was not available in every case; the distribution of the known cases is shown in Table $I$.

\section{Methods}

All the specimens were examined in London using the definitions and criteria of Byers and others (1970). Three basic classes of lesion are recognized (Fig. 1, overleaf).

(l) Osteophytes (a) Without evidence of cartilage growth (b) With evidence of cartilage growth.

(2) Cartilage lesions of limited progression These can be graded in several stages.

(3) Progressive cartilage lesions.

\section{Results}

\section{CAUCASIAN HIP JOINTS}

Byers and others (1970) studied 530 hip joints, but reported the results in only 375 right hip joints. Features (Fig. 1) in all categories increased in prevalence and severity with age. The more prevalent lesions of limited progression appeared as early as the first decade; these were of minimal severity. The most prevalent as well as the most advanced changes in this category were found in the 6th and 7th decades

Table I Age distribution of 32 Chinese hip joints and 11 Indian femoral heads

\begin{tabular}{|c|c|c|c|c|c|c|c|c|c|c|}
\hline \multirow[t]{2}{*}{ Race } & \multicolumn{10}{|c|}{ Age group (yrs) } \\
\hline & -9 & -19 & -29 & -39 & -49 & -59 & -69 & -79 & -89 & Not known \\
\hline Chinese & & & & & & 12 & 5 & 5 & 2 & 8 \\
\hline Indian & & 2 & 1 & 2 & 4 & 1 & 1 & & & \\
\hline
\end{tabular}

Accepted for publication July 10, 1973. 


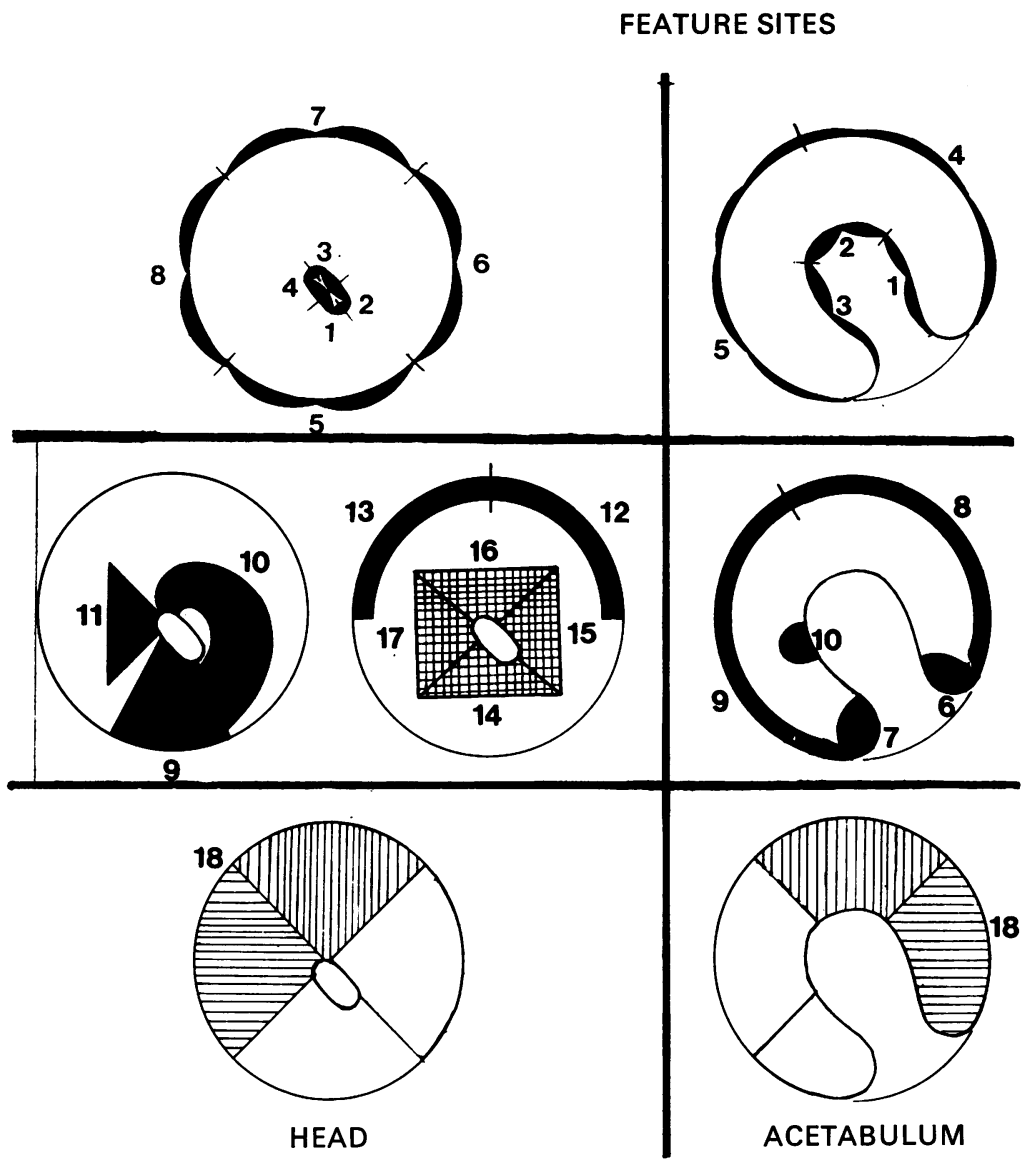

FEATURE

CHARACTERISTICS

\section{Osteophytes: \\ Stage 1 Ossification only \\ 2 Growth and ossification}

Limited Progression: 9-13 Stage 1 Granularity 2 Fraying 3 Loss of tissue 4 Ossification 5 Bone exposuro 14-17 No stages apart from size

Progression: Stage 1 Fraying 2 Exposure of bone

FIG. 1 Schematic representation of sites affected in head and acetabulum by the better-defined features described by Byers and others (1970), with a summary of the tissue changes

( 80 per cent.). Thereafter the number and severity of these limited changes declined; this observation could be the result of sampling, but could also be a manifestation of the reduction in the number and severity of changes found in femoral heads from an aged population with fractured femoral necks (Foss and Byers, 1972).

The progressive lesions were found first in the 4th decade at a much lower level of prevalence ( 3 per cent.) and showed a slight increase in the later decades (10 per cent.).

\section{CHINESE HIP JOINTS}

None of these joints showed progressive changes, but all the sites of the limited lesions described by Byers and others (1970) were affected in varying degrees (Tables II and III). The gross appearance of the changes was similar in the early stages, but seemed to differ somewhat in their later development. In addition, there were still small osteophytes, many of which were growing (Stage 2). Figs 2 and 3 illustrate some of these changes.
INDIAN FEMORAL HEADS

None of these heads showed progressive changes, but all the other lesions could be identified in one or another specimen (Table II). Two heads had growing osteophytes, although none was very large. Figs 4 and 5 show some of these changes. Here too the gross pattern of the changes in later stages differed a little from that seen in Caucasians. In addition, some heads had unfamiliar irregularities of the cartilage, mainly in the form of slight differences in level, marked by a smooth palpable edge about $0.25 \mathrm{~mm}$. in height of some parts of the cartilage.

\section{COMPARISON OF JOINTS}

It would be wrong to make a close comparison between Indian and Hong Kong or London specimens, partly because of the differences in age distribution, and partly because of the small numbers.

The greater number of Chinese joints can be crudely compared with the same Caucasian age group of Byers and others (1970) if one assumes that all the Chinese were aged 50 to 90 years. Tables IV and V 


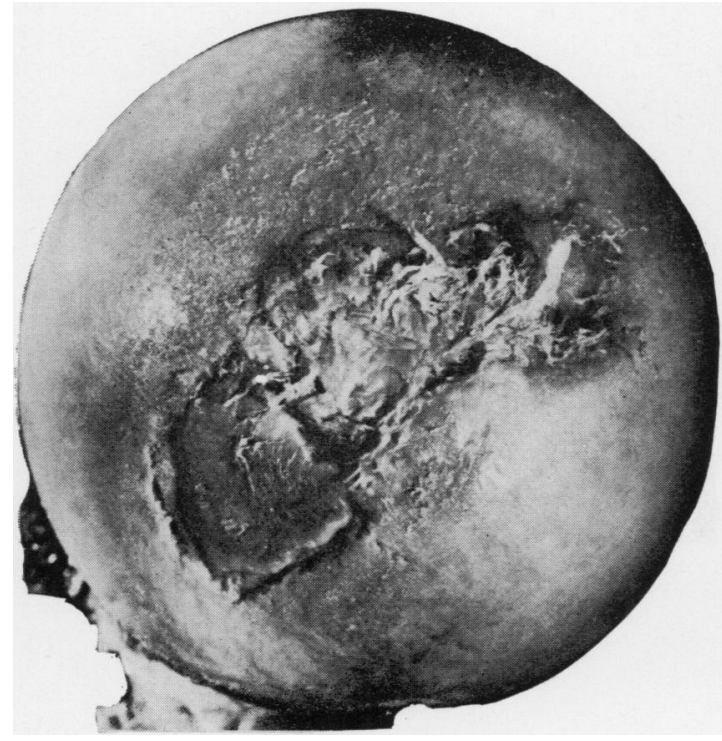

FIG. 2

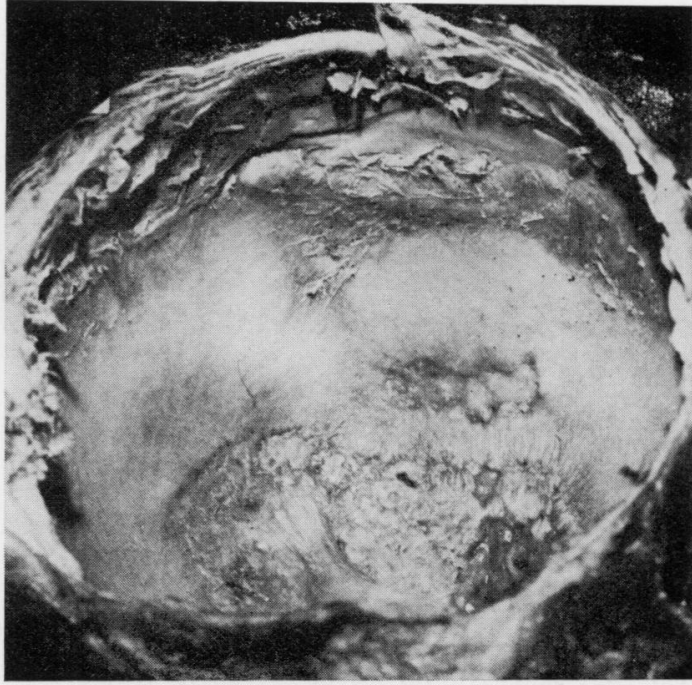

FIG. 3

FIGS 2 AND 3 Left hip joint, Hong Kong Chinese male, aged 53 yrs. The femoral head has two discrete lesions near the fovea, and frayed cartilage above and below it. The latter can be classified as part of Features 9 (below) and 10 (above and behind the fovea), Stage 2. The former lesions present an unisual appearance in comparison with Caucasian specimens, but have been classified as advanced stages of Features 9(Stage 4) and 11(Stage 3). In the acetabulum there is a growing osteophyte at the foveal margin (Feature 2, Stage 2). At the junction of labrum and cartilage there is a band of dark frayed cartilage; the labrum is detached on the left (Feature 8, Stage 2). Running down from this across the cartilage is a dark band with some superficial fraying (Feature 17). The sharply demarcated pit is an unusual finding in Caucasian joints, and is classed as 'miscellaneous'

Table II Features occurring in Chinese and Indian femoral heads classified according to Byers and others (1970).

\begin{tabular}{|c|c|c|c|c|c|c|}
\hline \multirow[t]{2}{*}{ Features } & \multicolumn{2}{|l|}{ Negative } & \multicolumn{2}{|l|}{ Stage 1} & \multicolumn{2}{|c|}{ Stage 2 or more } \\
\hline & Hong Kong & Amritsar & Hong Kong & Amritsar & Hong Kong & Amritsar \\
\hline $1-4$ & 27 & 9 & 2 & 0 & 3 & 2 \\
\hline $5-8$ & 27 & 11 & 1 & 0 & 4 & 0 \\
\hline 9 & 8 & 4 & 22 & 6 & 2 & 1 \\
\hline 10 & 31 & 7 & 1 & 3 & 0 & 1 \\
\hline 11 & 29 & 11 & 2 & 0 & 1 & 0 \\
\hline 12 & 26 & 6 & 6 & 5 & 0 & 0 \\
\hline 13 & 11 & 8 & 19 & 2 & 2 & 1 \\
\hline 14-17 & 23 & 9 & 8 & 1 & 1 & 1 \\
\hline
\end{tabular}

give the percentage prevalence of the better defined features for the two populations. In the interval since 1970 , Byers' method of classification has been modified by further studies (unpublished results), so that less emphasis is placed on Stage 1 osteophytes, and more on changes around the outer edge of the acetabulum; this accounts at least in part for the very large differences between the two populations in Stage 1 osteophytes and in the first stage of Features 8 and 9 in the acetabulum. It may also be the case that the relatively minor character of the changes in Chinese heads led to a more acute inspection with recognition of changes in Features 12 and 13 which were ignored in Caucasians. But the similarities are as striking as 


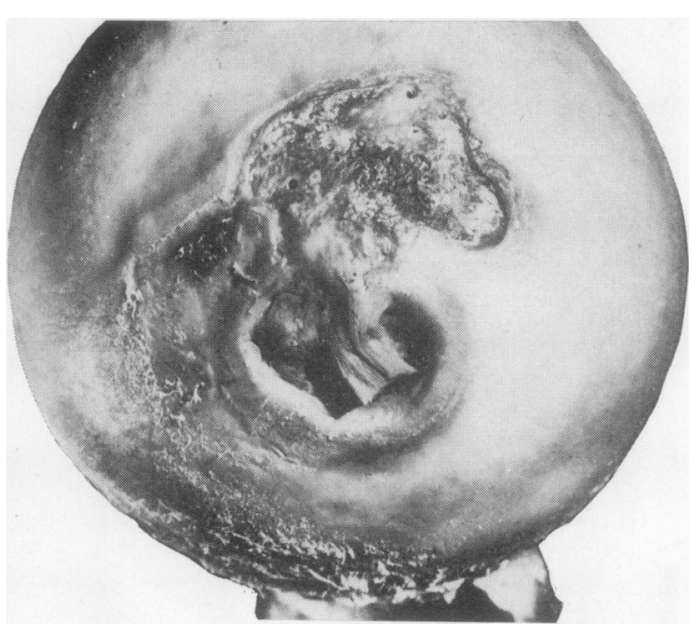

FIG. 4 Right femoral head, Indian male, aged 59 yrs. There are small growing foveal osteophytes (Features 1-4, Stage 2). Fraying of the cartilage is present below and in front of the fovea (Features 9 and 11, Stage 2). The sharply demarcated parafoveal lesion is classed as Feature 16; in Caucasians these usually have a smoother and shinier base. The ligamentum tores is small.

Table III Numbers of acetabula from Chinese hip joints showing various features classified according to Byers and others (1970)

\begin{tabular}{|c|c|c|c|}
\hline \multirow[t]{2}{*}{ Features } & \multicolumn{3}{|l|}{ Stage } \\
\hline & Negative & Stage 1 & Stage 2 or more \\
\hline $1-3$ & 21 & 6 & 5 \\
\hline 6 & 26 & 1 & 2 \\
\hline 7 & 31 & 1 & 0 \\
\hline 8 & 7 & 22 & 3 \\
\hline 9 & 8 & 19 & 5 \\
\hline 10 & 30 & 2 & 0 \\
\hline
\end{tabular}

Features 4 and 5, osteophytes developing in the labrum, have been left out because they cannot be easily detected or graded without fine detail $x$-ray, an examination which has not been carried out in these specimens.

Features 11 to 16 in Fig. 2 are too ill-defined for adequate classification (see original paper).

Feature 17, which is thought to represent the site of one limb of the tri-radiate cartilage, was present in 28 of the acetabula.

the differences. Features 14 to 17 , lesions relatively easy to recognize with confidence, are comparable in prevalence. So too are growing osteophytes. Although primary* osteoarthritis is very rare in the Chinese, there is a high proportion of growing osteophytes, which substantiates the radiological observations of Hoaglund and others (1973), of Danielsson (1964), and of Byers and others (1970) that osteophytes alone are not predictive in the diagnosis of osteoarthritis.

* Primary = no disease or joint deformity before onset of osteoarthrosis.

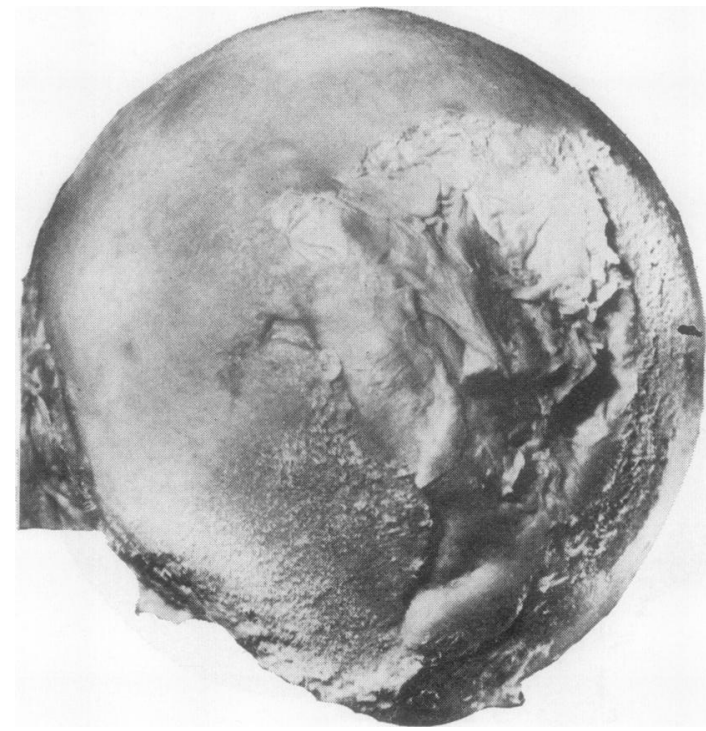

FIG. 5 Right femoral head, Indian male, 60 yrs. There is fraying of the cartilage above and behind the fovea (Feature 10, Stage 2) and below it (Feature 9, Stage 2). But in addition the latter site has a projection of ossifying cartilage (Feature 9, Stage 4). There is a sharply demarcated, small, smooth based lesion anterior to the fovea (Feature 17); a little fraying of the cartilage nearby may be classed as Feature 11, Stage 2 .

Table IV Prevalence (per cent.) of features in head of 286 hip joints of Caucasians aged between 50 and 90 years in London $(L)$ and of 32 hip joints of Chinese assumed to be aged between 50 and 90 years in Hong Kong (HK).

\begin{tabular}{|c|c|c|c|c|c|c|}
\hline \multirow[t]{2}{*}{ Features } & \multirow[t]{2}{*}{ Area } & \multicolumn{5}{|c|}{ Stages } \\
\hline & & 1 & 2 & 3 & 4 & Total \\
\hline \multirow[t]{2}{*}{$1-4$} & $\mathbf{L}$ & 70 & 10 & & & 80 \\
\hline & HK & 6 & 9 & & & 15 \\
\hline \multirow[t]{2}{*}{$5-8$} & $\mathbf{L}$ & 30 & 13 & & & 43 \\
\hline & HK & 3 & 12 & & & 15 \\
\hline \multirow[t]{2}{*}{9} & $\mathbf{L}$ & 48 & 15 & 10 & 6 & 79 \\
\hline & HK & 68 & 6 & 0 & 0 & 74 \\
\hline \multirow[t]{2}{*}{10} & $\mathbf{L}$ & $\overline{20}$ & 12 & 5 & 10 & 47 \\
\hline & HK & 3 & 0 & 0 & 0 & 3 \\
\hline \multirow[t]{2}{*}{$12-13$} & $\mathbf{L}$ & 26 & 9 & & & 35 \\
\hline & HK & 60 & 6 & & & 66 \\
\hline \multirow[t]{2}{*}{ 14-17 } & $\mathbf{L}$ & 31 & & & & 31 \\
\hline & HK & 28 & & & & 28 \\
\hline
\end{tabular}


Table V Prevalence (per cent.) of features in acetabulum of 286 hip joints of Caucasians aged between 50 and 90 years in London (L) and of 32 hip joints of Chinese assumed to be aged between 50 and 90 years in Hong Kong $(H K)$

\begin{tabular}{|c|c|c|c|c|c|c|}
\hline \multirow[t]{2}{*}{ Features } & \multirow[t]{2}{*}{ Area } & \multicolumn{5}{|c|}{ Stages } \\
\hline & & 1 & 2 & 3 & 4 & Total \\
\hline \multirow[t]{2}{*}{$1-3$} & $\mathbf{L}$ & 54 & 7 & & & 61 \\
\hline & HK & $\overline{19}$ & 16 & & & 35 \\
\hline \multirow[t]{2}{*}{$6-8$} & $\mathbf{L}$ & 35 & 2 & & & 37 \\
\hline & HK & 3 & 7 & & - & 10 \\
\hline \multirow[t]{2}{*}{7} & $\mathbf{L}$ & 14 & 2 & & - & 16 \\
\hline & HK & 3 & 0 & & & 3 \\
\hline \multirow[t]{2}{*}{8} & $\mathbf{L}$ & 18 & 28 & 11 & 1 & 58 \\
\hline & HK & $\overline{71}$ & 6 & 3 & 0 & 80 \\
\hline \multirow[t]{2}{*}{9} & $\mathbf{L}$ & 8 & 20 & 3 & 2 & 33 \\
\hline & HK & 61 & 6 & 10 & 0 & 77 \\
\hline
\end{tabular}

\section{Discussion}

The finding of articular cartilage changes in hip joints from populations in which primary osteoarthrosis rarely occurs that are comparable to those of limited progression in Caucasian hips confirms that these changes are not related to osteoarthrosis.

The number and severity of many of these lesions of limited progression was less than is found in Caucasians. This invites speculation on the aetiology and pathogenesis of both limited and progressive lesions and suggests that studies of large numbers of hip joints in a variety of populations correlated with the medical and social history of the individuals might be rewarding. Comparative biophysical studies are also essential to test the various extant hypotheses concerning the aetiology and pathogenesis of osteoarthrosis.

This study is part of a research programme supported by the Arthritis and Rheumatism Council. It could not have been undertaken without the cooperation of colleagues in the Pathology Departments in Hong Kong and Amritsar. The photographs were taken by T. R. Davis, A.R.P.S.

\section{References}

Byers, P. D., Contepomi, C. A., And Farkas, T. A. (1970) Ann. rheum. Dis., 29, 15 (A post mortem study of the hip joint)

Danielsson, L. G. (1964) Acta orthop. scand., Suppl. 66 (Incidence and prognosis of coxarthrosis)

Foss, M. V. L., AND Byers, P. D. (1972) Ann. rheum. Dis., 31, 259 (Bone density, osteoarthrosis of the hip, and fracture of the upper end of the femur)

Hoaglund, F. T., Yau, A. C. M. C., ANd Wong, W. L. (1973) J. Bone Jt Surg., 55A, 545 (Osteoarthritis of the hip and other joints in Southern Chinese in Hong Kong. Incidence and related factors)

MukhopadhaYA, B., AND BAROOAH, B. (1967) Indian J. Orthop., 1, 55 (Osteoarthritis of hip in Indians) 